\title{
Habilidades sociais e competência social: Analisando conceitos ao longo das obras de Del Prette e Del Prette
}

Camila Negreiros Comodo

Talita Pereira Dias

\section{RESUMO}

Considerando a diversidade conceitual do campo das Habilidades Sociais, tanto entre diferentes autores, como para um mesmo autor ao longo de suas obras, este estudo objetivou analisar as definições de habilidades sociais e competência social, a partir das obras de Del Prette e Del Prette. As definições dos conceitos foram selecionadas de livros e artigos teóricos desses autores, desde 1996 até 2012, e comparadas, em ordem cronológica. Com base nessas análises, observaram-se diferenças importantes em ambos os conceitos, ao longo das obras dos autores, produto de revisões, complementações e aprimoramentos de conhecimentos conceituais, empíricos e metodológicos que ocorreram ao longo do tempo.

Palavras-chaves: habilidades sociais, competência social, revisão conceitual.

\section{ABSTRACT}

Social skills and social competence: Analyzing concepts over the works of Del Prette and Del Prette

Considering the conceptual diversity of the field of Social Skills observed among different authors and in different works of the same author, this paper analyzed the definitions of social skills and social competence, based on the different works of Del Prette and Del Prette. Definitions of the concepts were selected from books and theoretical articles of those authors from 1996 to 2012, and comparisons were made in chronological order. Based on these analyses, important differences were observed in the definitions of social skills and social competence all over the works of the authors, which are product of revisions, additions and improvements of conceptual, empirical and methodological knowledge that occurred over the time

Keywords: social skills; social competence; conceptual review.

\section{HISTÓRICO DO CAMPO TEÓRICO E PRÁTICO DAS HABILIDADES SOCIAIS}

O campo teórico-prático das Habilidades Sociais (THS) surgiu na Inglaterra, em 1967, com estudos de Argyle sobre ergonomia e sistemas homem-máquina (Del Prette \& Del Prette, 1996, 1999; Falcone, 2001). Argyle (1967/1994) propôs uma transposição do conceito de habilidade na interação homem-máquina para as interações humanas, destacando algumas semelhanças ao comparar esses dois tipos de interação.

Esse campo teórico-prático busca identificar, definir, avaliar e promover as habilidades sociais e os demais fatores associados ao julgamento da competência social do indivíduo (Del Prette \& Del Prette, 2001). Além disso, de acordo com Del Prette e De Prette (2001), o campo busca examinar a associação entre um repertório bem elaborado, ou deficitário, de habilidades sociais com o desenvolvimento saudável ou com diferentes quadros nosológicos. Assim como procura compreender as etapas de desenvolvimento ao longo da vida e as possibilidades da promoção de habilidades sociais por meio de programas estruturados.

\section{Sobre os Autores}

C.N.C.

orcid.org/0000-0002-2862-2480

Instituto de Terapia por

Contingências de Reforçamento

(ITCR) - Campinas, SP

cami_nc@hotmail.com

T.P.D.

orcid.org/0000-0001-8811-3613

Centro Universitário de

Votuporanga (UNIFEV) -

Votuporanga, SP

talitapsi10@yahoo.com.br

\section{Direitos Autorais}

Este é um artigo de acesso aberto e pode ser reproduzido livremente, distribuído, transmitido ou modificado, por qualquer pessoa desde que usado sem fins comerciais. 0 trabalho é disponibilizado sob a licença Creative Commons CCBY-NC. 


\section{INTERACÃO EM LF PSICOLOGIA}

Embora o campo das Habilidades Sociais tenha se constituído como teórico-prático, compartilhando premissas e situando as habilidades sociais como foco de investigação, avaliação e intervenção, ele é permeado de controvérsias conceituais entre os autores. Algumas dessas divergências se referem a posições diferentes sobre a origem do campo, diversidade de matrizes teóricas, propostas práticas de promoção de habilidades sociais e, em particular, à definição de conceitos norteadores da pesquisa e atuação.

Em relação à origem do campo, para alguns autores, como Caballo (1996), ele seria derivado do Treinamento Assertivo, surgido com Wolpe e popularizado nos Estados Unidos, na década de 1970, com a obra intitulada "Your perfect right", de Alberti e Emmons (1970). Já para outros, como Del Prette e Del Prette $(1996,1999)$ e Falcone (2001), o campo das Habilidades Sociais e o Treinamento Assertivo seriam movimentos distintos que ocorreram concomitantemente no tempo, porém em países diferentes, com destaque para as contribuições de Argyle, na Inglaterra.

Quanto ao referencial teórico a ser adotado em pesquisas e intervenções, o campo das Habilidades Sociais apresenta uma diversidade conceitual, com propostas alternativas ou complementares sobre as habilidades sociais. Ao longo do seu desenvolvimento, esse campo contou com a contribuição e a influência de diversas teorias psicológicas, como a abordagem cognitivo-comportamental, a análise do comportamento e a psicologia social-cognitiva de Bandura (Del Prette $\&$ Del Prette, 2011). Essa diversidade de matrizes teórico-metodológicas resultou em definições não suficientemente uniformes de conceitos e escolhas de diferentes estratégias de avaliação e intervenção sobre o comportamento social dentro do campo das Habilidades Sociais. Tal variabilidade conceitual pode ser visualizada também ao se analisar as definições dos dois termos chaves do campo, como habilidades sociais e competência social. Observa-se que diferentes autores empregam definições diversificadas sobre esses termos. Por exemplo, para Caballo (1996) esses conceitos seriam sinônimos, enquanto para outros pesquisadores, os conceitos seriam relacionados, porém diferentes entre si (Del Prette \& Del Prette, 2011; Gresham, 2009; McFall, 1982; Trower, 1995).

A diversidade das definições não se restringe aos diferentes autores, ela também está presente, inclusive, ao longo das obras de um mesmo autor. Um dos fatores que parece contribuir para que isso ocorra é o fato do campo ainda estar em construção e aprimoramento. No Brasil, os primeiros trabalhos no campo do THS surgiram na década de 1970, com o estudo de Del Prette (1978). Mas, apenas a partir da década de 1990, observa-se um maior número de publicações de alguns autores, entre os quais se destacam Almir Del Prette e
Zilda A. P. Del Prette, para a sistematização do conhecimento, por meio de publicação mais sistemática de livros e artigos.

Por ainda estar em construção e consolidação no Brasil, o campo do THS apresenta uma constante atualização de suas bases teóricas, metodológicas e práticas, em função de achados advindos de pesquisas, atividades práticas e discussões teóricas dos estudiosos, entre outros. Ao se considerar as obras dos autores pioneiros do THS no Brasil, que são Del Prette e Del Prette, pode-se verificar que, desde o artigo considerado inaugural do campo no Brasil (Del Prette \& Del Prette, 1996) houveram alterações e aperfeiçoamentos dos conceitos de habilidades sociais e competência social. No decorrer de suas publicações, esses autores apresentaram definições dos constructos em questão com diferenciações que podem ser analisadas como revisões e aprimoramentos da base conceitual.

De modo geral, as diferenças encontradas nas definições podem ser interpretadas como positivas, no sentido de indicar constante aperfeiçoamento e atualização, mas essas também são indicativas da necessidade de cuidados na seleção das definições a serem adotadas nos novos estudos sobre o campo das Habilidades Sociais. Constatando-se que as definições propostas nas obras de Del Prette e Del Prette para os conceitos de habilidades sociais e competência social têm norteado decisões metodológicas (por exemplo, métodos de avaliação a serem adotados) e práticas (como procedimentos de intervenção) nesse campo de atuação, defende-se a necessidade de análise dessas formulações ao longo do tempo, de modo a contextualizá-las e permitir que os estudiosos do campo escolham, com critério, quais definições irão adotar em suas investigações.

\section{ESTUDOS DE REVISÃO DE HABILIDADES SOCIAIS NO CONTEXTO BRASILEIRO}

No Brasil, observam-se alguns esforços no sentido de organizar e sistematizar o que já foi produzido no campo do THS. Quanto a revisões de programas de intervenção em THS pode ser citado o estudo de Murta (2005). Já em relação a estudos de revisão de publicações brasileiras nesse campo podem ser citados os estudos de Bolsoni-Silva et al. (2006), de Fumo, Manolio, Bello e Hayashi (2009) e de Dias, Oliveira e Freitas (2011).

0 estudo de Bolsoni-Silva et al. (2006) teve como foco uma análise das publicações em periódicos no campo do THS, até 2004. Nessa revisão, foi observado um predomínio de artigos empíricos e de caracterização e poucos artigos teóricos, principalmente envolvendo revisões conceituais (constando de apenas dois: Del Prette \& Del Prette, 1996 e de Mitsi, Silveira, \& Costa, 2004). Uma das justificativas dos au- 


\section{INTERACÃO EM LF PSICOLOGIA}

tores para a baixa produção de estudos teóricos publicados é que esses provavelmente viriam subsequentes aos estudos empíricos, que funcionariam como requisito para análises conceituais. No entanto, deve-se destacar que o status atual de produção de conhecimento no campo do THS já permite a realização de tais estudos.

O estudo de Fumo et al. (2009) buscou analisar a produção científica do campo do THS, considerando a coleção de livros Sobre Comportamento e Cognição. Dos 27 capítulos identificados, mais da metade dos estudos (16) foram classificados como conceituais, sendo, portanto, divergente dos resultados de Bolsoni-Silva et al. (2006). Essa divergência foi explicada pelo tipo de fonte de busca adotada (capítulos de livros).

Novas propostas de análises conceituais também podem trazer informações importantes para a compreensão desse campo no país. Considerando isso, Dias et al. (2011) realizaram uma análise conceitual sequenciada tendo como foco a construção da definição do método vivencial, ao longo das obras de Del Prette e Del Prette, que foram os proponentes do conceito no campo. As autoras delinearam uma trajetória do conceito, a partir de uma análise cronológica das obras dos autores.

Como se observa, os estudos de revisão (Murta, 2005; Bolsoni-Silva et al., 2006), exceto o estudo de Fumo et al. (2009), mostram a predominância de artigos empíricos e de intervenção, em detrimento de pesquisas conceituais. No entanto, somente um estudo (Dias et al., 2011) realizou análise histórico-conceitual, com foco nas revisões de conceitos que caracterizam esse campo em construção no país. Ao defender que análises conceituais, tal como a realizada por Dias et al. (2011), podem ser adotadas para outros conceitos, o presente estudo focalizou aqueles fundamentais para a identidade desse campo: habilidades sociais e competência social.

Esse tipo de análise se justifica pelo crescimento de publicações na área, aprimoramentos ao longo do tempo e pelas diferentes definições de conceitos importantes encontradas no campo. Considerando esses aspectos, o presente estudo teve como objetivo analisar as definições de habilidades sociais e competência social, tomando como base as diferentes elaborações feitas por Del Prette e Del Prette, comparando-as ao longo do tempo.

\section{MÉTODO}

\section{BASE DOCUMENTAL:}

O corpus de publicações a serem analisadas no presente estudo foi composto das produções de Almir Del Prette e Zilda A. P. Del Prette. A escolha dessas produções justifica-se pelas seguintes razões: (a) o pioneirismo desses autores na pesquisa e prática desse campo no país; (b) a alta frequência de citações desses autores observadas nos estudos de revisão e de questões conceituais (Bolsoni-Silva et al., 2006; Fumo et al., 2009); (c) a grande produção de pesquisas desses autores no Brasil e na América do Sul (Morán \& Olaz, 2014).

Foram selecionados para análise os livros autorais e artigos teóricos e conceituais sobre o campo das Habilidades Sociais produzidos integralmente por Del Prette e Del Prette no período de 1996 (publicação do artigo considerado inaugural do campo no Brasil) a 2012 (última publicação teóricoconceitual até o presente momento). Não foram foco de análise aquelas obras que apresentavam definições como forma de contextualização do estudo, reafirmando definições já publicadas. Sendo assim, foram excluídos da presente análise livros em que Del Prette e Del Prette contribuíram com capítulos que não tinham como objetivo a discussão teórica. Também foram excluídos estudos empíricos que não se propunham a realizar uma discussão sobre os conceitos de habilidades sociais e competência social.

Em relação a isso, foi realizada uma análise preliminar de todos os artigos em que Del Prette e Del Prette foram autores ou coautores que constam no site do grupo Relações Interpessoais e Habilidades Sociais (RIHS), totalizando 131 estudos. Foi constatado que, desses, 52 dos artigos não definem habilidades sociais e competência social. Desse modo, dos 79 artigos que apresentam as definições desses termos, 61 retomam as definições de Del Prette e Del Prette presentes nos estudos de 1999, 2001, 2005 e 2012, seis citam autores de outros países como McFall ou Caballo, oito apresentam a definição apenas de alguma classe específica de habilidades sociais, como empatia, assertividade ou habilidades sociais educativas e quatro estudos não estavam disponíveis para consulta. A partir desse dado, somado com o foco em analisar apenas artigos ou livros autorais de Del Prette e Del Prette em que esses pesquisadores discutem os termos habilidades sociais e competência social, optou-se por analisar exatamente essas publicações que foram contextualizadas nos 61 artigos.

\section{PROCEDIMENTO}

Primeiramente, foi realizada uma busca dos livros e dos artigos assinados por Del Prette e Del Prette na página web do grupo RIHS sob a responsabilidade deles. 0 site em questão possui uma lista de todas as publicações do grupo RIHS, desde artigos, livros, capítulos de livros, teses e dissertações. Em seguida, essas publicações foram lidas e foram selecionados os trechos dos livros ou artigos em que os autores apresentavam e discutiam as definições dos conceitos de habilidades sociais e competência social. Dessas obras, foram 


\section{2." INTERACÃO EM PSICOLOGIA}

examinadas somente as definições apresentadas para estes dois conceitos, buscando-se uma análise do significado da definição, de suas diferenças em relação às definições anteriores e de suas possíveis implicações ou aplicações. Por essa razão, o presente estudo restringiu-se à análise das definições de habilidades sociais e competência social apresentadas pelos autores, não tendo como pretensão realizar uma análise do conteúdo geral dos livros e artigos.

Com a seleção dos trechos dos livros e artigos, foram feitas comparações entre as definições, considerando a ordem cronológica das obras. Inicialmente, essas comparações foram realizadas individualmente pelas duas autoras do estudo, ambas pesquisadoras do campo das Habilidades Sociais. As análises realizadas foram discutidas pelas pesquisadoras em termos de concordância, discordância e complementaridades. Essas análises, realizadas preliminarmente pelas autoras, foram sistematizadas em três produtos intermediários: (a) uma mesa redonda no IV Seminário Internacional de Habilidades Sociais, realizado em Niterói no ano de 2013; (b) um seminário realizado pelo grupo RIHS em São Carlos em 2014; (c) uma apresentação no encontro da Associação Nacional de Pesquisa e Pós-Graduação em Psicologia, em 2014, no grupo de trabalho Relações Interpessoais e Competência Social. Com base no registro das discussões suscitadas em cada uma dessas apresentações, foram refinadas as análises do presente estudo.

\section{RESULTADOS E DISCUSSÃO}

No Apêndice estão discriminadas em ordem cronológica as obras de Del Prette e Del Prette que foram analisadas para o presente trabalho, de acordo com os critérios de inclusão e exclusão explicitados. Junto com o nome das obras, seguem as siglas referentes a elas, as quais são utilizadas neste estudo. Nessa Tabela 1 também são apresentados os conceitos de habilidades sociais e de competência social contidos em cada um dos trabalhos analisados.

Ao observar as definições de habilidades sociais e competência social apresentadas, nota-se que desde a primeira obra Del Prette e Del Prette (1996) já diferenciavam esses conceitos. Nesse aspecto, Del Prette e Del Prette (1996, 1999, $2001,2005,2010 / 2012$ ) se aproximam de diversos autores do campo do THS que também entendem esses conceitoschaves como distintos (e.g. MacFall, 1982; Gresham, 2009). Esses conceitos de habilidades sociais e competência social são discutidos a seguir, procurando identificar alterações importantes nas definições ao longo do tempo.

\section{ANÁLISES DO CONCEITO DE HABILIDADES SOCIAIS:}

Em termos do conceito de habilidades sociais, em Habilidades Sociais: uma área em desenvolvimento (HSAD) (Del Prette \& Del Prette,1996) e em Psicologia das Habilidades Sociais (PHS) (Del Prette \& Del Prette, 1999), Del Prette e Del Prette trataram esse constructo de forma bastante abrangente, não especificando, nem qualificando o tipo de desempenho que deveria ser apresentado nas interações sociais para ser classificado como habilidades sociais. Com as definições apresentadas, o conceito de habilidades sociais se sobrepunha ao de desempenho social, podendo incluir qualquer comportamento social e, portanto, também comportamentos ativos/ agressivos e passivos.

Já em Psicologia das Relações Interpessoais (PRI) (Del Prette \& Del Prette, 2001) e em Psicologia das Habilidades Sociais na Infância (PHSI) (Del Prette \& Del Prette, 2005), observa-se um avanço na direção de qualificar o comportamento social a ser denominado como habilidade social. Nesses livros, os autores explicitaram o conceito de habilidades sociais, diferenciando-o de outros desempenhos sociais, como o passivo e o agressivo. Assim, torna-se mais clara a diferenciação entre desempenho social e habilidades sociais. Entretanto, nessas obras, partes das definições de habilidades sociais ainda parecem necessitar de especificações. Em PRI (Del Prette \& Del Prette, 2001) não fica explicitado o que seria lidar "de maneira adequada" com as demandas das situações interpessoais, e em PHSI (Del Prette \& Del Prette, 2005) os autores também não especificaram o que seria "favorecer o relacionamento saudável e produtivo com as demais pessoas". É possível que uma descrição mais operacional desse trecho da definição sanasse dúvidas e minimizasse possíveis interpretações da definição.

Na publicação de PHSI (Del Prette \& Del Prette, 2005) há uma novidade em termos do conceito de habilidades sociais, uma vez que Del Prette e Del Prette apontaram na definição desse constructo que as habilidades sociais contribuem para a competência social, o que sugere que os dois conceitos em questão não podem ser analisados e entendidos de forma independente, o que está em consonância com McFall (1982). Aprofundando essa análise, pode-se questionar se as habilidades sociais necessariamente contribuem para a competência social. Um exemplo que pode ser citado é o caso de pessoas com traços de psicopatia: elas diversas vezes apresentam comportamentos sociais que poderiam ser classificados como classes de habilidades sociais. No entanto, tais comportamentos não contribuem para a competência social, principalmente, por não atingirem os critérios ético-morais defendidos pelos autores como necessários para que o desempenho seja avaliado como socialmente competente (es- 


\section{H. INTERACÃO EM PSICOLOGIA}

ses critérios serão discutidos a seguir, na seção sobre as definições de competência social). Nesse sentido, uma posição menos controversa sobre esse ponto seria a de que as habilidades sociais são condição para competência social, mas não seriam definidas como comportamentos que obrigatoriamente contribuem para a competência social, o que estava apenas implícito nos critérios de competência social.

Em Habilidades Sociais e Análise do Comportamento: proximidade histórica e atualidades (HSAC), Del Prette e Del Prette (2010/2012) explicitaram com mais detalhes a relação entre os conceitos de habilidades sociais e de competência social. Primeiramente, os autores afirmaram que as habilidades sociais contribuem para a competência social, mas complementaram que, embora sejam necessárias, as habilidades sociais não são suficientes para se classificar um desempenho como socialmente competente. Além da maior especificação da relação entre competência social e habilidades sociais nessa publicação, outro ponto que cabe destaque é a tentativa dos autores em definir o conceito de habilidades sociais utilizando termos e uma forma de análise próprios da Análise do Comportamento como a referência à alta probabilidade de produção de consequências reforçadoras para o indivíduo e o grupo social. Essa aproximação entre o campo teórico-prático das Habilidades Sociais e a Análise do Comportamento não é uma proposta inédita de Del Prette e Del Prette (2010/2012), havendo alguns poucos estudos no Brasil nessa direção, como, por exemplo, os artigos de Bolsoni-Silva (2002) e de Bolsoni-Silva e Carrara (2010). Essas propostas mostram como o referencial da Análise do Comportamento é uma abordagem importante para o campo das Habilidades Sociais. Entretanto, mesmo com a aproximação entre esse campo e a Análise do Comportamento, não há uma restrição para o uso dos conceitos de habilidades sociais e competência social somente numa perspectiva teórica. Ao contrário disso, são observados trabalhos que demonstram a influência e contribuições de outras abordagens no campo das Habilidades Sociais, como pode ser visto no capítulo de Caballo, Irurtia e Salaza (2009) que trata das contribuições da psicologia cognitiva-comportamental, e de Olaz, (2009) que aborda as influencias da Teoria Social-Cognitiva, ambos capítulos do livro "Psicologia das Habilidades Sociais: diversidade teórica e suas implicações", além do artigo de Saldaña, Del Prette e Del Prette (2002).

\section{ANÁLISES DO CONCEITO DE COMPETÊNCIA SOCIAL}

O conceito de competência social sofreu alterações e complementações ao longo das obras de Del Prette e Del Prette. Alguns aspectos importantes dessas mudanças serão analisados aqui, como, por exemplo, a que se refere à competência social: um constructo, uma capacidade, um comporta- mento; qual seria o tipo de avaliação (externa ou do próprio indivíduo) que pode ser feita sobre o desempenho social; quais critérios são importantes para a competência social; e, qual é o papel da articulação entre os componentes do desempenho socialmente competente.

Um primeiro ponto a ser analisado é o que se pode chamar de competência social. Em PHS Del Prette e Del Prette (1999) classificaram competência social de duas formas diferentes. Num primeiro momento, os autores afirmaram que ela seria o desempenho social, o que é diferente de dizer que ela seria a avaliação desse comportamento. Ainda, em um segundo momento nessa obra, os autores colocaram competência social como uma capacidade do indivíduo. Levanta-se então a questão sobre o que seria a competência social: uma capacidade, uma avaliação ou um desempenho. Já em HSAD (Del Prette \& Del Prette, 1996), PRI (Del Prette \& Del Prette, 2001), PHSI (Del Prette \& Del Prette, 2005) e HSAC (Del Prette \& Del Prette, 2010/2012), Del Prette e Del Prette não se referiram mais à competência social como desempenho, mas como avaliação dos efeitos desse desempenho e/ou como capacidade aprendida pelo indivíduo em efetuar a articulação entre os componentes do desempenho social.

Uma vez que os autores afirmaram, na maioria das obras analisadas, que a competência social tem um caráter avaliativo, cabe discutir quem faria essa avaliação. Em HSAD, Del Prette e Del Prette (1996) afirmaram que a competência social é uma avaliação exclusivamente externa, não mencionando nesse ponto a possibilidade de uma avaliação do próprio indivíduo sobre seu desempenho. Essa pode ser uma tentativa de tornar a avaliação do desempenho mais objetiva, o que pode ser visto como uma vantagem. Entretanto, perde-se, com a avaliação externa, a possibilidade de aferir aspectos importantes aos quais apenas o próprio indivíduo tem acesso, como seus sentimentos e pensamentos. Já em PHS (Del Prette \& Del Prette, 1999) e nas obras posteriores, os autores passaram a explicitar a possibilidade de uma avaliação externa e/ou do próprio indivíduo acerca do desempenho social, mostrando a importância da autoavaliação nesse campo.

Outra questão a ser pontuada se refere aos critérios que devem ser levados em consideração na avaliação do desempenho socialmente competente. Em PHS, Del Prette e Del Prette (1999) já apresentaram, desde esse primeiro livro, critérios para que o indivíduo seja considerado socialmente competente (a consecução dos objetivos de uma situação interpessoal; a manutenção ou melhoria de sua relação com o interlocutor, incluindo-se aí a busca de equilíbrio do poder e das trocas nessas relações; a manutenção ou melhoria da autoestima; e a manutenção ou ampliação dos direitos humanos socialmente reconhecidos), o que contribuiu para a operacionalização desse conceito. 


\section{INTERACÃO EM PSICOLOGIA}

Esses critérios apresentados se mantêm ao longo das obras dos autores, tendo uma pequena variação na obra PHSI (Del Prette \& Del Prette, 2005), uma vez que esse livro se refere às habilidades sociais na infância e Del Prette e Del Prette consideraram que nessa fase do desenvolvimento critérios específicos devem ser avaliados, tais como os comportamentos adaptativos constatados como correlatos da competência social. Ainda, no artigo HSAC (Del Prette \& Del Prette, 2010/2012) se percebe uma variação na linguagem utilizada para se referir aos critérios de competência social, uma vez que essa publicação dialoga especificamente com a Análise do Comportamento, abordagem que possui uma linguagem técnica específica. Por exemplo, em PHS (Del Prette \& Del Prette,1999) os autores mencionaram como critério para a competência social a manutenção ou melhoria da autoestima, e em HSAC, Del Prette e Del Prette (2010/2012) substituíram o termo "autoestima" por correlatos emocionais positivos, termo que parece mais coerente com a linguagem da Análise do Comportamento.

Ainda com relação aos critérios de competência social, no livro PHS Del Prette e Del Prette (1999) mencionaram que esses critérios são atingidos simultaneamente para garantir a competência social. A expressão "simultaneamente" passa a impressão de que todos os critérios devem ser atingidos para que o desempenho seja considerado socialmente competente. Entretanto, nas publicações posteriores, os autores tornaram evidente que a competência social pode envolver níveis variados, em termos da qualidade e da quantidade de critérios atingidos, de modo que um desempenho social pode ser avaliado em um continuum de competência social (Del Prette \& Del Prette, 2001; 2005; 2010/2012).

Outro ponto a ser discutido, considerando os critérios de competência social, é que, desde PHS (Del Prette \& Del Prette, 1999), os autores apontaram que o desempenho socialmente competente não pode ser definido apenas como a obtenção de objetivos próprios na interação. Para Del Prette e Del Prette (1999; 2001; 2005; 2010/2012), a competência social é um conceito mais abrangente, que inclui também consequências positivas para os interlocutores e para a comunidade social do indivíduo. Essa concepção se consolida em HSAC, artigo no qual Del Prette e Del Prette (2010/2012) afirmaram que os critérios de competência social estão contemplados em duas dimensões: a dimensão instrumental - relacionada com consequências imediatas e para o próprio indivíduo - e a dimensão ético-moral - relacionada com consequências de médio e longo prazo para o indivíduo e também para a comunidade. Sendo assim, nem todos os critérios de competência social precisam ser atingidos simultaneamente, porém, não basta apenas que o indivíduo atinja os objetivos da interação, alguns critérios da dimensão ético-moral da competência social devem ser con- templados para que o desempenho seja avaliado como socialmente competente

Essa preocupação com a cultura, com a ética e com os direitos humanos são explicitados em HSAC (Del Prette \& Del Prette, 2010/2012) por meio da dimensão ético-moral da competência social podem ser observados também nas obras anteriores. Quando Del Prette e Del Prette apontaram, em PHS (1999) e em PHSI (2005), que a competência social supõe a articulação entre componentes comportamentais, fisiológicos e cognitivos do desempenho às demandas da situação e da cultura, fica implícito que o desempenho do indivíduo ocorre dentro de uma comunidade que determina padrões aceitáveis e inaceitáveis de comportamento e uma avaliação do desempenho social precisa considerar o papel dessa cultura.

Ainda em relação aos critérios de competência social, os autores não fizeram referência a formas e procedimentos específicos para se avaliar esses critérios em programas de pesquisa. Desse modo, não é abordado, ao longo das obras, como as dimensões instrumental e ético-moral podem ser aferidas e como elas se relacionam ao se avaliar um desempenho como socialmente competente. Assim, caberiam alguns questionamentos a respeito dessas dimensões: a dimensão instrumental seria uma condição para a dimensão ético moral, ou elas seriam independentes? Haveria uma hierarquia de dificuldade ou de importância entre essas dimensões? Ao se considerar um continuum na avaliação de competência social, pode-se questionar se os critérios instrumentais seriam mais facilmente atingidos do que os éticomorais? Seria necessário atingir critérios de ambas as dimensões para se considerar um desempenho socialmente competente, ou atingir critérios de uma dimensão só seria suficiente?

Por fim, destaca-se que a articulação entre componentes do desempenho social é um aspecto da definição que se mantém ao longo das obras de Del Prette e Del Prette e, portanto, parece ser um elemento fundamental para a competência social. Mesmo no artigo HSAC (Del Prette \& Del Prette, 2010/2012), quando os autores se dirigem especificamente aos leitores da Análise do Comportamento, esse aspecto também está presente ao afirmarem que "atribuição de competência social supõe correspondência entre comportamentos manifestos e encobertos" (p. 108).

Embora esse elemento da articulação entre componentes do desempenho social tenha sido apontado na maioria das obras analisadas, existem algumas diferenças entre as definições sobre qual seria o papel dessa articulação. Em PHS (1999) Del Prette e Del Prette afirmaram que a competência social supõe a capacidade de articular os componentes comportamentais, fisiológicos e cognitivos do desempenho. Já 
em PRI (Del Prette \& Del Prette, 2001) e PHSI (Del Prette \& Del Prette, 2005), a competência social é vista como a própria capacidade de articulação. A partir dessas diferenças coloca-se a questão do que seria essa articulação: um pré-requisito da competência social, um produto dela ou, ainda, um processo inerente à competência social? Uma possibilidade de interpretação para esse aspecto seria a diferenciação entre critérios de processo e critérios de produto da competência social. Nos primeiros critérios, a correspondência entre comportamentos públicos e encobertos seria inerente ao processo do desempenho socialmente competente. Nos critérios de produto, a coerência estaria associada às consequências que os comportamentos socialmente competentes produzem: a manutenção ou melhora da autoestima dos envolvidos, a manutenção ou melhora da qualidade da relação, a aprovação social, o equilíbrio de perdas e ganhos entre os envolvidos e o respeito aos direitos humanos básicos.

\section{CONSIDERAÇÕES FINAIS}

A análise dos conceitos de habilidades sociais e competência social, ao longo das obras de Del Prette e Del Prette, permite observar uma série de revisões, aprimoramentos e complementações. A partir da análise dos conceitos, pode-se observar que, embora haja uma relação bastante estreita e bem definida entre os conceitos de habilidades sociais e competência social, fica também clara a razão de diferenciálos: enquanto as habilidades sociais são condição fundamental para a competência social, a competência social requer o atendimento a critérios que vão além daqueles aplicados às habilidades sociais, principalmente ao se considerar a dimensão ético-moral vinculada a aspectos culturais e de atendimento a direitos humanos.

Uma limitação do presente estudo está relacionada ao procedimento adotado na análise das definições: para tornar mais viável a análise optou-se pela seleção de trechos específicos que continham a definição de cada conceito, em detrimento da avaliação das publicações completas. Muito embora as análises tenham sido realizadas de modo a contextualizar as definições na proposta geral dos autores, é possível que, em alguns momentos, a análise tenha se restringido ao trecho com a definição. No entanto, essa tarefa de examinar obras completas tem sua importância e pode ser realizada em estudos posteriores.

De todo modo, a análise dos conceitos de forma sequenciada, apresentada neste estudo, permite verificar uma evolução dos conceitos, tanto referente ao termo de habilidades sociais como ao de competência social, o que pode sugerir que, ao adotar uma definição em algum estudo no campo das Habilidades Sociais, a utilização dos conceitos contidos nas obras mais recentes possa ser mais pertinente. Isso não significa, de modo algum, uma análise em termos de qualificação de cada definição, com maior valorização da mais atual. Ao contrário disso, o que se procura no presente artigo é demonstrar a importância de cada definição para a construção do campo na atualidade. Desse modo, cada definição apresentada pareceu funcionar como um "andaime" para a seguinte. Tal análise remete à ideia proposta por Antunes (2008) sobre a tridimensionalidade do tempo, de modo que uma análise mais bem contextualizada permite "a compreensão do passado, que estrutura o presente e se projeta para o futuro" (p.45).

Feita a compreensão do passado para a estruturação do presente, cabe agora as projeções para o futuro. E, em relação isso, essa proposta de análise conceitual constitui um convite para diálogos com demais estudiosos do campo. De modo algum o presente trabalho pretende esgotar a análise dos conceitos, mas ao contrário, objetiva fomentar reflexões e diálogos posteriores, concordantes ou não com a proposta apresentada. Assim, o que se tem como final é um novo recomeço para discussões históricas, teóricas e conceituais no campo teórico-prático do THS. Considerando que Almir Del Prette e Zilda Del Prette continuam produzindo no campo do THS, essas futuras discussões também podem ser realizadas a partir de novas elaborações que esses autores poderão produzir sobre tais conceitos.

\section{CONTRIBUIÇÃO DE CADA AUTOR}

C.N.C. e T.P.D. contribuiram para a análise formal dos dados, conceitualização, investigação, metodologia e redação.

\section{DECLARAÇÃO DE CONFLITO DE INTERESSES}

Os autores declaram que não há conflitos de interesse neste artigo.

\section{REFÊRENCIAS}

Alberti, R. E., \& Emmons, M. L. (1970). Your perfect right. Califórnia: Impact.

Antunes, M. A. M. (2008). Psicologia escolar e educacional: história, compromissos e perspectivas. Psicologia Escolar e Educacional, 12, 469-475. http://dx.doi.org/10.1590/S1413-85572008000200020.

Argyle, M. (1967/1994). La habilidade social. Em M. Argyle. Psicologia del comportamiento interpersonal (pp. 58-77). Madrid: Alianza Universidad. 


\section{W MTERAC̄OOEM ET PSICOLOGIA}

Bolsoni-Silva, A. T. B. (2002). Habilidades sociais: Breve análise da teoria e da prática a luz da análise do comportamento. Interação em Psicologia, 6(2), 233-242. http://dx.doi.org/10.5380/psi.v6i2.3311

Bolsoni-Silva, A. T. B., \& Carrara, K. (2010). Habilidades sociais e análise do comportamento: Compatibilidades e dissensões conceitual-metodológicas. Psicologia em Revista, 16 (2), 330-350. http://dx.doi.org/ 10.5752/P.16789563.2010v16n2p330

Bolsoni-Silva, A. T. B., Del Prette, Z. A. P., Del Prette, G., Montagner, A. R., Bandeira, M., \& Del Prette, A. (2006). Habilidades sociais no Brasil: Uma análise dos estudos publicados em periódicos. Em M. Bandeira, Z. A. P. \& Del Prette, A. Del Prette (Org.), Estudos sobre habilidades sociais e relacionamento interpessoal (pp.17-45). São Paulo: Casa do Psicólogo.

Caballo, V. E. (1996). O treinamento em habilidades sociais. Em V. E. Caballo (Org), Manual de técnicas de terapia e modificação de comportamento (pp. 361-398). São Paulo: Livraria Santos Ed.

Caballo, V. E., Irurtia, M. J., \& Salazar, I. C. (2009). Abordagem cognitiva na avaliação e intervenção sobre habilidades sociais. Em Z. A. P. Del Prette \& A. Del Prette (Orgs.), Psicologia das Habilidades Sociais: Diversidade teórica e suas implicações (pp. 67-108). Petrópolis, RJ: Vozes.

Del Prette, A. (1978). O treino assertivo na formação do psicólogo. Arquivos Brasileiros de Psicologia Aplicada, 30, 5355.

Del Prette, A., \& Del Prette, Z. A. P. (2001). Psicologia das relações interpessoais: Vivências para o trabalho em grupo $\left(6^{\mathrm{a}}\right.$ ed.). Petrópolis, RJ: Vozes.

Del Prette, A. \& Del Prette, Z.A.P. (2011). Enfoques e modelos do treinamento de habilidades sociais. In: A. Del Prette \& Z.A.P. Del Prette (Orgs). Habilidades sociais: intervenções efetivas em grupo (p.19-56). São Paulo: Casa do Psicólogo.

Del Prette, Z. A. P., \& Del Prette, A. (1996). Habilidades sociais: Uma área em desenvolvimento. Psicologia: Reflexão e Crítica, 9(2), 287-389.

Del Prette, Z. A. P., \& Del Prette, A. (1999). Psicologia das habilidades sociais: Terapia e educação. Petrópolis: Vozes.

Del Prette, Z. A. P., \& Del Prette, A. (2005). Psicologia das habilidades sociais na infância: Teoria e Prática. (1 ed.). Petrópolis: Vozes.

Del Prette, Z. A. P., \& Del Prette, A. (2010/2012). Social skills and behavior analysis: Historical proximity and new issues. Perspectivas em Análise do Comportamento, 1, 104115 [versão em língua inglesa de artigo brasileiro, originalmente publicado em 2010].

Dias, T. P., Oliveira, P. A., \& Freitas, M. L. P. F. (2011). 0 método vivencial no campo das Habilidades Sociais: Construção histórico-conceitual e sua aplicação. Estudos e Pesquisas em Psicologia, 11, 472-487.

Falcone, E. (2001) Habilidades sociais para além da assertividade. Em R. C. Wielenska, (Org.), Sobre comportamento e cognição: Questionando e ampliando a teoria e as intervenções clínicas e em outros contextos. (vol. 6, pp. 202-212). Santo André: ESETec.

Fumo, V. M. S., Manolio, C. L., Bello, S., \& Hayashi, M. C. P. I. (2009). Produção científica em habilidades sociais: Estudo bibliométrico. Revista Brasileira de Terapia Comportamental e Cognitiva, 11(2), 246-266.

Gresham, F. M. (2009). Análise do comportamento aplicada às habilidades sociais. Em Z. A. P. Del Prette \& A. Del Prette (Eds.), Psicologia das Habilidades Sociais: Diversidade teórica e suas implicações (pp.17-66). Petrópolis: Vozes.

McFall, R. M. (1982). A review and reformulation of the concept of social skills. Behavioral Assessment, 4, 1-33.

Mitsi, C. A., Silveira, J. M., \& Costa, C. E. (2004). Treinamento de habilidades sociais no tratamento do transtorno obsessivo-compulsivo: Um levantamento bibliográfico. Revista Brasileira de Terapia Comportamental e Cognitiva, 6(1), 49-59.

Morán, V. E., \& Olaz, F. O. (2014). Instrumentos de evaluación de habilidades sociales em América Latina: Um análisis bibliométrico. Revista de Psicologia: Universidad de Chile, 23(1), 93-105. http://dx.doi.org/10.5354/07190581.2014.32877

Murta, S. G. (2005). Aplicações do treinamento em habilidades sociais: análise da produção nacional. Psicologia: Reflexão e Crítica, 18(2), 283-291. http://dx.doi.org/10.1590/S0102-79722005000200017

Olaz, F. O. (2009). Contribuições da Teoria Social-Cognitiva de Bandura para o Treinamento de Habilidades Sociais. Em Z. A. P. Del Prette \& A. Del Prette (Orgs.). Psicologia das Habilidades Sociais: Diversidade teórica e suas implicações (pp. 109-148). Petrópolis, RJ: Vozes.

Saldaña, M. R. R., Del Prette, A., \& Del Prette, Z. A. P. (2002). Em H. J. Guilhardi, M. B. B. Madi, P. P. Queiroz, \& M. C. Scoz (Orgs.), Sobre comportamento e cognição: Contribuições para a construção da teoria do comportamento (pp. 269-283). Santo André: ESETec.

Trower, P. (1995). Adult social skills: State of the art and future directions. Em W. O’Donohue \& L. Krasner (Orgs.), Handbook of psychological skills training: Clinical techniques and applications. Nova York: Allyn and Bacon.

Recebido em 24/01/2017 Primeira decisão editorial em 28/03/2017 Aceito em 09/05/2017

Nota: As autoras agradecem aos professores Almir Del Prette e Zilda Aparecida Pereira Del Prette pelas discussões durante a elaboração desse material. 
Tabela 1. Obras analisadas de Del Prette e Del Prette e os conceitos de habilidades sociais e competência social contidos nessas publicações.

\begin{tabular}{|c|c|c|}
\hline Obras & Conceito de Habilidades Sociais & Conceito de Competência Social \\
\hline $\begin{array}{l}\text { Artigo: Habilidades sociais: Uma } \\
\text { área em desenvolvimento. (1996) } \\
\text { Sigla: HSAD. }\end{array}$ & $\begin{array}{l}\text { "todo e qualquer desempenho emitido em } \\
\text { interações sociais" (p.242) }\end{array}$ & $\begin{array}{l}\text { "uma avaliação externa da proficiência do desempenho social, inferida das consequências das } \\
\text { ações dos indivíduos em interação" (p. 241-242). }\end{array}$ \\
\hline $\begin{array}{l}\text { Livro: Psicologia das habilidades } \\
\text { sociais: Terapia e educação. } \\
\text { (1999) } \\
\text { Sigla: PHS. }\end{array}$ & $\begin{array}{l}\text { "conjunto de desempenhos apresentados pelo } \\
\text { indivíduo diante das demandas de uma } \\
\text { situação interpessoal" (p. 47) }\end{array}$ & $\begin{array}{l}\text { "comportamento que produz melhor efeito no sentido de equilibrar reforçadores e assegurar } \\
\text { direitos humanos básicos" (p. 46). } \\
\text { "capacidade do indivíduo (autoavaliada ou avaliada por outros) em apresentar um desempenho } \\
\text { que garanta, simultaneamente: (a) a consecução dos objetivos de uma situação interpessoal; (b) } \\
\text { a manutenção ou melhoria de sua relação com o interlocutor, incluindo-se aí a busca de equilíbrio } \\
\text { do poder e das trocas nessas relações; (c) a manutenção ou melhoria da autoestima; d) a } \\
\text { manutenção ou ampliação dos direitos humanos socialmente reconhecidos" (p. 47). } \\
\text { Os critérios de funcionalidade citados "supõem, portanto, a capacidade do indivíduo em articular } \\
\text { os componentes do seu desempenho (comportamentais, cognitivo-afetivos e fisiológicos) às } \\
\text { demandas interpessoais da situação e da cultura" (p. 48). }\end{array}$ \\
\hline $\begin{array}{l}\text { Livro: Psicologia das relações } \\
\text { interpessoais: Vivências para o } \\
\text { trabalho em grupo. (2001) } \\
\text { Sigla: PRI. }\end{array}$ & $\begin{array}{l}\text { "classes de comportamentos sociais no } \\
\text { repertório do indivíduo para lidar de maneira } \\
\text { adequada com demandas das situações } \\
\text { interpessoais" (p. } 31 \text { ) }\end{array}$ & $\begin{array}{c}\text { "efeitos do desempenho social nas situações vividas pelo indivíduo [...], à capacidade do indivíduo } \\
\text { de organizar pensamentos, sentimentos e ações em função de seus objetivos e valores } \\
\text { articulando-os às demandas imediatas e mediatas do ambiente" (p 31). }\end{array}$ \\
\hline $\begin{array}{l}\text { Livro: Psicologia das habilidades } \\
\text { sociais na infância: Teoria e } \\
\text { Prática. }(2005) \\
\text { Sigla: PHSI. }\end{array}$ & $\begin{array}{l}\text { "diferentes classes de comportamentos sociais } \\
\text { do repertório de um indivíduo, que contribuem } \\
\text { para a competência social, favorecendo um } \\
\text { relacionamento saudável e produtivo com as } \\
\text { demais pessoas" ( } \mathrm{p} 31 \text { ) }\end{array}$ & $\begin{array}{c}\text { "capacidade de articular pensamentos, sentimentos e ações em função de objetivos pessoais e } \\
\text { de demandas da situação e da cultura, gerando consequências positivas para o indivíduo e para a } \\
\text { sua relação com as demais pessoas" ( } \mathrm{p} 33 \text { ). } \\
\text { "análise de funcionalidade se baseia nos efeitos do desempenho, com maior ênfase em três tipos } \\
\text { gerais e complementares de resultados: alcançar objetivos, manter ou melhorar a qualidade dos } \\
\text { relacionamentos e manter ou melhorar a autoestima" (p 34). }\end{array}$ \\
\hline
\end{tabular}


Tabela 1. Obras analisadas de Del Prette e Del Prette e os conceitos de habilidades sociais e competência social contidos nessas publicações. (continuação)

Obras

Conceito de Habilidades Sociais

"um comportamento social é classificado como habilidades socia is quando contribui para a competência social em uma tarefa de interação social" (p. 106).

"a disponibilidade de um repertório de

Artigo: Social skills and behavior analysis: Historical proximity and new issues. (2010/2012) Sigla: HSAC habilidades sociais é condição necessária, mas

não suficiente para a competência social" (p.106)

"subordinadas aos critérios da competência social, as habilidades sociais constituem,

portanto, uma classe geral de comportamentos que possuem alta probabilidade de produzir consequências reforçadoras para o indivíduo e para as demais pessoas do seu grupo social" (p. 107).
Conceito de Competência Social

"atributo avaliativo de um comportamento ou conjunto de comportamentos bem sucedidos

conforme determinados critérios de funcionalidade - em uma interação social" (p. 106).

Critérios de competência social: "(a) a consecução do objetivo, em termos de consequências específicas da "tarefa social", tanto em termos de reforçamento positivo (por exemplo, solicitar um favor e obtê-lo) como de reforçamento negativo, no sentido de remover ou evitar estimulação aversiva (por exemplo, expressar desagrado ao comportamento do outro e, com isso, interrompê-

lo); (b) a aprovação social da comunidade verbal (em geral relacionada à forma e ocasião do desempenho); (c) a manutenção ou melhora da qualidade da relação (e.g., respeito mútuo e prazer da convivência)" (p. 107); e equilíbrio de "reforçadores" e respeito aos "direitos humanos básicos" (p. 107)

"tomados em conjunto, os critérios de competência social articulam duas dimensões de funcionalidade - instrumental e ético-moral - que estão relacionadas, respectivamente, com as consequências imediatas e com as consequências atrasadas do episódio interativo e também

com consequências para o indivíduo e para o seu interlocutor ou grupo social" (p. 107)

"como os correlatos emocionais e as consequências de médio e longo prazo estão incluídas nos critérios de competência social, a atribuição de competência social supõe correspondência entre comportamentos manifestos e encobertos" (p 108). 